EGU2020-10047

https://doi.org/10.5194/egusphere-egu2020-10047

EGU General Assembly 2020

(c) Author(s) 2021. This work is distributed under

the Creative Commons Attribution 4.0 License.

\title{
The active North Ligurian domain: new geophysical insight from the SEFASILS cruise
}

\author{
Jean-Xavier Dessa ${ }^{1}$, Marie-Odile Beslier ${ }^{1}$, Laure Schenini ${ }^{1}$, Serge Sambolian ${ }^{1}$, Albane Canva ${ }^{1}$, \\ Alessandra Ribodetti ${ }^{1}$, Stéphane Operto ${ }^{1}$, Mohamed Bachir Miguil ${ }^{1}$, Nicolas Chamot-Rooke ${ }^{2}$, Nicola \\ Corradi $^{3}$, Matthias Delescluse ${ }^{2}$, Jacques Déverchère ${ }^{4}$, and Christophe Larroque ${ }^{1}$ \\ ${ }^{1}$ UMR Geoazur, Univ. Côte d'Azur, Sorbonne Université, Obs. Côte d'Azur, CNRS, IRD, Valbonne, France \\ ${ }^{2}$ Laboratoire de Géologie, École Normale Supérieure, PSL Research University, CNRS, Paris, France \\ ${ }^{3}$ DISTAV, Universita di Genova, Corso Europa, 26, 16132 Genoa, Italy \\ ${ }^{4}$ Laboratoire Géosciences Océan, UBO, CNRS, IUEM, Plouzané, France
}

The first leg of the SEFASILS cruise took place in November 2018 onboard the RV Pourquoi-Pas ? Up-to-date multichannel and wide-angle seismic data were acquired offshore Monaco, from margin to basin, aiming at providing a renewed vision of the complex North Ligurian backarc system. The compressive and extensive tectonic phases that have closely alternated in time and space over the last 45 My have yielded fairly contrasting structures, whose understanding is rendered even more challenging by the strong overprint of the Messinian salt tectonics. There is ample evidence of a compressive reactivation of the North Ligurian margin since $5 \mathrm{Ma}$ at least, especially to the East, along the Gulf of Genoa. Such deformation is associated with some notable seismicity originating from faults and mechanisms that remain poorly apprehended. Yet, this seismicity peaked at one historical Mw 6.6-6.9 destructive event (1887 Ligurian earthquake). The main objective of the SEAFASILS effort is a better characterization of the crustal structures, and chiefly, of the active crustal faults and their potential interplay with salt tectonics beneath the margin and the northernmost part of the basin, both featuring seismicity. Linking these aspects with broader-scale lithospheric processes within the Southern Alps/Northern Apennines, addressed in the AlpArray initiative, is also of great importance. Here we present preliminary results of these seismic investigations, with time and prestack depth migrated MCS data. Emphasis was put on the construction of some suitable velocity models to get optimal focusing of structures from surface to depth. Some active crustal tomographic velocities derived from the dense OBS deployment providing complementary insight will also be presented. 